\title{
Sense of coherence and job characteristics in predicting burnout in a South African sample
}

\begin{tabular}{|c|c|}
\hline $\begin{array}{l}\text { Authors: } \\
\text { Claire S.Johns } \\
\text { Gideon P. de } \\
\text { Madelyn Gelo } \\
\text { Christina Gyö } \\
\text { Koorosh Mass } \\
\text { Jérôme Rossi }\end{array}$ & $\begin{array}{l}\text { on }^{1,2} \\
\text { ruin }^{1} \\
\text { enhuys } \\
\text { kös }^{3} \\
\text { oudi }^{3} \\
r^{3}\end{array}$ \\
\hline $\begin{array}{l}\text { Affiliations: } \\
{ }^{1} \text { Department } \\
\text { Psychology an } \\
\text { Management } \\
\text { Johannesburg }\end{array}$ & $\begin{array}{l}\text { f Industrial } \\
\text { d People } \\
\text { University of } \\
\text { South Africa }\end{array}$ \\
\hline $\begin{array}{l}{ }^{2} \text { NCCR LIVES, } \\
\text { Lausanne, Sw }\end{array}$ & $\begin{array}{l}\text { Jniversity of } \\
\text { tzerland }\end{array}$ \\
\hline $\begin{array}{l}{ }^{3} \text { Institute of } P \\
\text { University of } \\
\text { Switzerland }\end{array}$ & $\begin{array}{l}\text { ychology, } \\
\text { ausanne, }\end{array}$ \\
\hline $\begin{array}{l}\text { Corresponde } \\
\text { Claire Johnsto }\end{array}$ & $\begin{array}{l}\text { ce to: } \\
\text { n }\end{array}$ \\
\hline $\begin{array}{l}\text { Email: } \\
\text { claire.johnsto }\end{array}$ & @unil.ch \\
\hline $\begin{array}{l}\text { Postal addres } \\
\text { NCCR LIVES, } \\
\text { Lausanne, Qu } \\
\text { Mouline, Bâti } \\
\text { Bureau 5552, } \\
\text { Switzerland }\end{array}$ & $\begin{array}{l}\text { niversity of } \\
\text { artier UNIL- } \\
\text { nent Géopolis } \\
1015 \text { Lausanne, }\end{array}$ \\
\hline $\begin{array}{l}\text { Dates: } \\
\text { Received: } 18 \\
\text { Accepted: } 17 \\
\text { Published: } 09\end{array}$ & $\begin{array}{l}\text { eb. } 2013 \\
\text { uly } 2013 \\
\text { Oct. } 2013\end{array}$ \\
\hline $\begin{array}{l}\text { How to cite t } \\
\text { Johnston, C.S } \\
\text { Györkös, C., G } \\
\text { Massoudi, K., } \\
\text { (2013). Sense } \\
\text { and job chara } \\
\text { predicting bu } \\
\text { African sampl } \\
\text { of Industrial P } \\
\text { Tydskrif vir Be } \\
39(1), \text { Art. \#1 } \\
\text { http://dx.doi. } \\
\text { sajip.v39i1.10 }\end{array}$ & $\begin{array}{l}\text { is article: } \\
\text { de Bruin, G.P., } \\
\text { eldenhuys, M., } \\
\text { \& Rossier, J. } \\
\text { of coherence } \\
\text { teristics in } \\
\text { nout in a South } \\
\text { e. SA Journal } \\
\text { sychology/SA } \\
\text { dryfsielkunde, } \\
96,9 \text { pages. } \\
\text { rg/10.4102/ } \\
96\end{array}$ \\
\hline $\begin{array}{l}\text { Copyright: } \\
\text { (C) 2013. The } \\
\text { Licensee: AOS } \\
\text { OpenJournals } \\
\text { is licensed un } \\
\text { Creative Com } \\
\text { Attribution Lic }\end{array}$ & $\begin{array}{l}\text { uthors. } \\
\text { IS } \\
\text { This work } \\
\text { ler the } \\
\text { nons } \\
\text { ense. }\end{array}$ \\
\hline Read online: & \\
\hline 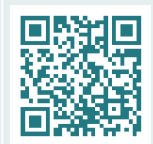 & $\begin{array}{l}\text { Scan this QR } \\
\text { code with your } \\
\text { smart phone or } \\
\text { mobile device } \\
\text { to read online. }\end{array}$ \\
\hline
\end{tabular}

Orientation: Research that considers the effects of individual characteristics and job characteristics jointly in burnout is necessary, especially when one considers the possibility of curvilinear relationships between job characteristics and burnout.

Research purpose: This study examines the contribution of sense of coherence (SOC) and job characteristics to predicting burnout by considering direct and moderating effects.

Motivation for this study: Understanding the relationships of individual and job characteristics with burnout is necessary for preventing burnout. It also informs the design of interventions.

Research design, approach and method: The participants were 632 working adults (57\% female) in South Africa. The measures included the Job Content Questionnaire, the Sense of Coherence Questionnaire and the Maslach Burnout Inventory. The authors analysed the data using hierarchical multiple regression with the enter method.

Main findings: Job characteristics and SOC show the expected direct effects on burnout. SOC has a direct negative effect on burnout. Job demands and supervisor social support show nonlinear relationships with burnout. SOC moderates the effect of demands on burnout and has a protective function so that the demands-burnout relationship differs for those with high and low SOC.

Practical/managerial implications: The types of effects, the shape of the stressor-strain relationship and the different contributions of individual and job characteristics have implications for designing interventions.

Contribution/value add: SOC functions differently when combined with demands, control and support. These different effects suggest that it is not merely the presence or absence of a job characteristic that is important for well-being outcomes but how people respond to its presence or absence.

\section{Introduction}

Several authors have highlighted the necessity to consider individual differences to improve our understanding of the relationships between job characteristics and strain (Rubino, Perry, Milam, Spitzmueller \& Zapf, 2012; Maslach, Schaufeli \& Leiter, 2001; Györkös, Becker, Massoudi, De Bruin \& Rossier, 2012), yet these differences remain a relatively understudied area. It is necessary to explore moderation effects in studies that combine job characteristics and individual differences. These types of studies can provide insight into the ways in which individual characteristics affect the stressor-strain relationship (Rubino et al., 2012). The Job Demand-Control (-Support) (JDC[S]) model explains how job characteristics contribute to job strain (Johnson \& Hall, 1988; Karasek, 1979).

The current authors supplement this model by jointly considering how individual differences, in the form of sense of coherence (SOC) (Antonovsky, 1979), and job characteristics affect burnout (Maslach \& Jackson, 1986). This type of research seems pertinent for South Africa where topics like burnout and work-related well-being are of key interest (Rothmann, 2003; Van der Colff \& Rothmann, 2009).

Burnout may develop in response to stressful work situations, like those with high job demands, low control and low social support (Johnson \& Hall, 1988; Karasek, 1979; Verhoeven, Maes, Kraaij \& Joekes, 2003). However, the likelihood of experiencing a strain response, like burnout, is not equal for all people. Variations in the appraisal of, and response to, characteristics of the work situation are a function of individual differences. Piedmont (1993) argued that burnout is: 'clearly associated with enduring qualities of the individual' (p. 469).

Therefore, the authors consider how the general orientation of SOC, which provides a foundation for successful coping (Antonovsky, 1993), modifies the relationship between job characteristics 
and burnout. Theoretically, there are grounds to consider the effects of SOC in the relationship between job characteristics and burnout.

SOC has negative correlations with the dimensions of burnout and helps to improve sense making of events, appraisal of whether resources are adequate to deal with events and increases feelings of control (Rothmann, Jackson \& Kruger, 2003). Specifically, SOC results in better perceptions of job characteristics, like those the authors find in the JDC[S] model of job strain (Feldt, Kivimäki, Rantala \& Tolvanen, 2004). These job characteristics - demands, control and social support - are important for a wide range of health and wellbeing outcomes (Schmidt \& Diestel, 2011).

The JDC[S] model (Johnson \& Hall, 1988; Karasek, 1979) provides a framework for understanding how job characteristics affect well-being. Despite the demonstrated usefulness of the JDC[S] model for understanding job strain (Häusser, Majzisch, Niesel \& Schulz-Hardt, 2010), researchers have identified two further areas of research. Firstly, the JDC[S] model overlooks the potentially important dimension of how individual differences influence perceptions and experiences of work situations (Van der Doef \& Maes, 1999). Secondly, previous research has indicated the presence of curvilinear relationships between job characteristic variables and well-being outcomes (De Jonge, Reuvers, Houtman, Bongers \& Kompier, 2000). Despite some studies that tested for curvilinear effects, most studies, as meta-analyses indicate, do not examine curvilinear effects (Häusser et al., 2010; Van der Doef \& Maes, 1999).

This research aims to address these two research needs by using the JDC[S] model, in combination with SOC, to examine the effect of this individual characteristic in the relationship between job characteristics and burnout. The authors extend previous work on the moderating effects of SOC (Rothmann et al., 2003; Söderfeldt, Söderfeldt, Ohlson, Theorell \& Jones, 2000) by proposing that SOC moderates the linear and nonlinear relationships between job characteristics (demands, control and support) and burnout. This is consistent with the research tradition that has considered the buffering effects of various personal resources in relation to job characteristics (Tremblay \& Messervey, 2011).

\section{Theoretical overview}

\section{The Job Demand-Control (-Support) model of job strain}

The JDC[S] model of job strain (Karasek, 1979; Johnson \& Hall, 1988) holds that three job characteristics (demands, control and social support) combine to influence workers' well-being in the workplace.

Demands refer to: "psychological stressors involved in accomplishing the work load, stressors related to unexpected tasks, and stressors of job related personal contact' (Karasek, 1979 , p. 289). Demands require constant attention in the forms of physical and/or psychological effort. Job control, or job decision latitude, refers to the control people have over their tasks and behaviour during the workday (Karasek, 1979). It includes aspects like participation in, and authority over, making decisions as well as skill discretion, so that workers can decide how to use their skills, resources and time to complete their work (Van der Doef \& Maes, 1999). Johnson and Hall (1988) extended the Karasek model to include social support as a resource that moderates the effects of demands. Researchers consider support from supervisors and coworkers separately because they may contribute differently to the possible reduction of burnout (Beehr, Bowling \& Bennett, 2010).

The JDC[S] model has been widely applied across occupational groups and tested in relation to various wellbeing outcomes. Job characteristics have different effects, depending on the well-being outcome at hand (De Jonge \& Schaufeli, 1998; 1999; Häusser et al., 2010). Researchers have provided strong cross-sectional support for the additive effects of demands, control and support on a variety of work and non-work related well-being outcomes (Häusser et al., 2010). Consequently, the authors expect the three job characteristics to have different relationships with burnout and propose the first hypothesis of this study: demands will show a positive relationship with burnout, whereas control and social support contribute to lower levels of burnout (Hypothesis 1) (Häusser et al., 2010; Van der Doef \& Maes, 1999; Verhoeven et al., 2003).

In addition to the effects of job characteristics on well-being, there have been two advancements in applying the JDC[S] model. One is investigating the curvilinear relationships between job characteristics and well-being outcomes (De Jonge et al., 2000; Rydstedt, Ferrie \& Head, 2006). The other is adding personal characteristics or resources to the JDC[S] model (Györkös et al., 2012).

In his vitamin model, Warr (1990) proposed that job characteristics, like vitamins in the body, might help up to a point, after which they can become detrimental or fail to have increasing positive effects. Therefore, in the case of burnout, the authors' second hypothesis proposes a U-shaped relationship between job characteristics and burnout. This suggests that levels of a job characteristic, which are too low or too high, could be harmful (Hypothesis 2). Insufficient demands may lead to boredom and frustration, whereas excessive demands contribute to distress and burnout (LeFevre, Matheny \& Kolt, 2003). The effect of demands on burnout may also depend partly on the person's appraisal of the demands as a challenge or hindrance stressor (Lepine, Podsakoff \& Lepine, 2005). Low levels of control may be associated with burnout because of an inability to meet demands. Alternatively, jobs with high levels of control are often the positions with high levels of uncertainty, responsibility for making decisions and the obligation for accepting liability for decisions or mistakes. They could also contribute to burnout (De Jonge \& Schaufeli, 1999). Low levels of social support may represent a lack of resources, whereas high levels of social support could become negative 
when, according to the stress transfer theory (Karasek, Triantis \& Chaudhry, 1982), less strained people absorb the strain of those around them.

Researchers have tested the non-linear propositions of the vitamin model. For a variety of different outcomes, researchers found curvilinear relationships of the expected U-shape for job demands and job decision latitude (Warr, 1990) as well as for job demands, job autonomy and social support (De Jonge \& Schaufeli, 1998; De Jonge et al., 2000). For demands and control, the curvilinear relationships are usually in the expected direction, but the results for social support have been less consistent. Researchers have found curvilinear relationships with an unexpected shape. They indicate that average levels of support correspond to high burnout (De Jonge, 1995; De Jonge \& Schaufeli, 1999) and low job satisfaction scores (Rydstedt et al., 2006).

Because this study is particularly interested in the moderating effect of SOC, it is prudent to include the curvilinear effects to ensure that its findings represent a true moderating effect. Excluding curvilinear effects may influence the chances of detecting moderating effects (Fletcher \& Jones, 1993; Ganzach, 1997). The presence of curvilinear effects also requires a different intervention approach. The solution of merely increasing or decreasing the relevant job characteristic (as the JDC[S] model defines it), without considering an optimal level, could fail to help (Adams \& White, 2005; LeFevre et al., 2003). Understanding the true nature of the relationship between job characteristics and burnout is crucial given the severe and chronic nature of burnout.

\section{Job burnout}

Job burnout is a form of strain specific to the work context and includes emotional exhaustion, depersonalisation or cynicism and reduced personal accomplishment (Maslach \& Jackson, 1986). Exhaustion refers to the draining of physical and mental energy, cynicism to a negative, detached and impersonal attitude at work and reduced personal efficacy to the belief that one is no longer effective at work. Negative self-evaluation and feelings of incompetence accompany them (Maslach et al., 2001; Rothmann, 2003). Burnout reduces a person's ability to work, solve work-related problems and develop professional efficacy. It is likely to lead to increased absenteeism, job turnover, loss of productivity and poor performance (Maslach \& Goldberg, 1998; Schaufeli, 2003). Given that burnout is an individual response to enduring stressors at work, dual attention to job characteristics and individual characteristics is necessary (De Beer, Pienaar \& Rothmann, 2013; Maslach \& Goldberg, 1998; Rothmann, 2003; Van der Colff \& Rothmann, 2009).

\section{Sense of coherence}

Antonovsky's (1979) SOC concept first developed from considering how stressors affect a person's health and physical well-being. This has broadened to include a person's psychological well-being (Feldt, 1997). SOC is part of the salutogenic paradigm that aims to understand how people live well and remain healthy despite exposure to stressors (Antonovsky, 1987). Therefore, SOC seems a relevant characteristic to consider in the relationship between job characteristics, work stressors, resources and burnout.

One can regard SOC as a broad individual attribute that influences the way people perceive and interpret events. It stimulates motivation and positive coping behaviours, like acquiring resources (Feldt et al., 2004). SOC is not a personality trait or a specific coping strategy. Rather, it is a general orientation that provides a basis for successful coping. It consists of three highly interrelated dimensions: comprehension, manageability and meaningfulness (Antonovsky, 1987; 1993). These three components of SOC help people to understand demands in their environment, manage challenges and attach meaning to their experiences (Antonovsky, 1987). Throughout childhood and adolescence, various experiences provide opportunities for developing SOC: consistency in life experiences contributes to comprehension, the availability of resources with which to respond to demands contributes to manageability and participation in valued activities increases meaningfulness (Feldt, Metsäpelto, Kinnunen \& Pulkkinen, 2007). Therefore, SOC develops because of life experiences. This suggests that it can change over time and is different from personality traits, which are stable behavioural tendencies (McCrae \& Costa, 1994).

Furthermore, a well developed SOC helps people to perceive situations and social environments and their accompanying demands as less stressful, threatening or anxiety provoking (Feldt et al., 2004; Rothmann et al., 2003). Consequently, the third hypothesis of this study is that SOC has a negative relationship with burnout (Hypothesis 3). Finally, the authors propose that SOC will moderate the effects of the job characteristic variables on burnout (Hypothesis 4). Hochwälder (2006) proposed that characteristics of the work environment do not have consistent relationships with mental health. Instead, their effect may vary as a function of individual differences. From this perspective, a moderating effect of SOC would change the way demands, control and support contribute to burnout. Previous studies that combined job characteristics and SOC in predicting burnout have been limited in their hypotheses. They normally only propose that SOC will moderate the effects of job demands in relation to well-being (Rothmann et al., 2003; Söderfeldt et al., 2000). The authors extend this work and test the moderating effect of SOC in relation to the three job characteristics included in the JDC[S] model: job demands, control and social support. As a salutogenic construct, SOC may protect people from the negative effects of work stressors in the form of high demands, low control and low support (Hanse \& Engström, 1999). SOC could moderate the effect of demands because people with strong SOC are more likely to interpret stressors in their environments favourably (Feldt et al., 2004). With regard to control, SOC may moderate its effect on burnout because people with high SOC have increased levels of perceived control (Rothmann et al., 2003). With regard to support, people with clear SOC are more likely to use the 
available social support resources and search for additional resources (Feldt et al., 2004). This suggests that, in the case of low social support, SOC could help to make up for this absence. Testing the moderating role of SOC on both the linear and curvilinear job characteristic variables should yield greater insight than will separate tests of individual and job characteristics (Györkös et al., 2012; Maslach \& Goldberg, 1998).

\section{Aims of this research}

This study aims to explore the function of SOC in predicting burnout in relation to the effects of the job characteristics. Firstly, the authors propose that demands will show positive linear relationships with burnout, whereas both support and control will have negative effects on burnout. Secondly, they explore the possibility of curvilinear relationships of a U-shape between job characteristics and burnout. Thirdly, they propose that SOC has a negative effect on burnout and a moderating effect on the relationships between job characteristics and burnout.

\section{Research design}

This study is cross-sectional with primary data collected at a single point in time.

\section{Research method}

\section{Participants}

The participants were 632 working adults in South Africa. The authors included them in the study by using convenience sampling. Master's students in industrial and organisational psychology used their networks to recruit participants for the study.

All participants had completed at least Grade 12, which is the end of high school education in South Africa, and were at least 18 years old $(M=34.42, \mathrm{SD}=11.38)$. Their ages ranged between 18 and 64 . The sample comprised $41.9 \%$ males $(n=265)$ and $57.3 \%$ females $(n=362)$. Missing values were because of non-responses.

With regard to education, $22.6 \%(n=143)$ of the participants had completed the final year of school, $22.2 \%(n=140)$ had obtained bachelor's degrees, 20.4\% $(n=129)$ had diplomas, $15.5 \%(n=98)$ had honours degrees, 10.8\% $(n=68)$ had certificates and one participant had completed a doctorate degree. Missing values were because of non-responses.

All the participants had employment with a minimum of one-year of work experience. They represented a variety of industries and organisations. Therefore, they do not represent a particular sector. The most commonly reported job titles were accountant $(n=18)$, administrator $(n=12)$, consultant $(n=10)$ and director $(n=8)$. The racial composition was: 351 (55.5\%) participants were White, 178 (28.2\%) were Black, 50 $(7.9 \%)$ were of mixed-race, $49(7.8 \%)$ were Asian and two $(0.3 \%)$ did not specify a race.

\section{Measuring instruments}

Job content questionnaire (JCQ): The authors assessed job characteristics with the 29-item JCQ (Karasek, 1979). It included nine items that measure psychological job demands, nine items that measure job control and 11 items that measure social support (six items for co-worker support and five items for supervisor support). For supervisor support, participants could indicate, 'I have no supervisor'. The authors scored all the items using a four-point scale that ranged from 1 ('completely disagree') to 4 ('completely agree'). The reliabilities are 0.76 for demands, 0.80 for control, 0.77 for supervisor and co-worker support and 0.79 for total support.

Maslach Burnout Inventory-General Survey (MBI-GS): The MBI-GS allows for the measurement of burnout beyond the traditional setting of human services in which the construct of burnout was first developed (Maslach \& Jackson, 1986). The MBI-GS includes items that measure emotional exhaustion (five items), cynicism (five items) and professional efficacy (six items). The authors scored the items using a seven-point Likert scale that ranged from 1 ('never') to 7 ('every day'). The professional efficacy scale is reverse scored so that a high score on the scale shows reduced efficacy (Schaufeli \& Salanova, 2007). The reliability is 0.90 for the total burnout scale.

Sense of coherence: This study used the 13-item version of the Sense of Coherence Questionnaire (SOC-13) with a unique seven-point scale for each item (Antonovsky, 1987; 1993). The scale contains items that reflect three sub-dimensions of meaningfulness, manageability and comprehensibility. However, one should use only the total score. Therefore, the authors used the total score only (Antonovsky, 1987; 1993). The SOC scale has a reliability of 0.62 .

\section{Research procedure}

The authors collected the data as part of a larger research study. They recruited participants with the help of master's students in industrial and organisational psychology. They asked the master's students to find participants who represented a wide range of occupations, status levels and race groups in South Africa. Participants needed to have at least one year of working experience, be 18 years or older and have finished Grade 12.

Participants did not receive any compensation for participating in the study. The covering letter the authors provided with the questionnaires gave full information about the research and emphasised that participation was voluntary. The authors regarded a returned and completed questionnaire as consent to participate.

\section{Statistical analysis}

Hierarchical multiple regression was the principal analytic tool the authors used in this study and they met the standard assumptions with respect to multicollinearity, 
homoscedasticity and normality of residuals. The authors centred all independent variables. To test the curvilinear hypotheses, they entered quadratic terms of the job characteristic variables into the regression analyses where necessary (Cohen, Cohen, West \& Aiken, 2002; Ganzach, 1997). Testing moderating effects requires one to compute an interaction term by multiplying the moderator by the independent variable (Cohen et al., 2002).

In each analysis, the authors controlled for age and gender in the first step. One should include variables that could correlate with the regressors or dependent variables in the model as controls (Antonakis, Bendahan, Jacquart \& Lalive, 2010; Brewer \& Shapard, 2004). Age and gender have shown a relationship with burnout (Pedrabissi, Rolland \& Santinello, 1993).

The authors proposed a separate hierarchical regression model for each job characteristic term. Following the recommendations of Ganzach (1997), to include quadratic and interaction terms in the same model, the authors set up the models as follows:

- Step 1 contained age and gender.

- Step 2 contained the linear job characteristic term.

- Step 3 contained the curvilinear job characteristic term.

- Step 4 contained the SOC term.

- Step 5 contained the linear interaction term of the job characteristic variable multiplied by SOC.

- Step 6 contained the curvilinear interaction term of the job characteristic variable multiplied by SOC.

\section{Results}

The authors conducted analyses for the three separate burnout dimensions first and then for burnout as a total score. The pattern of significant results and size of regression coefficients were the same regardless of whether they used the separate burnout dimensions or the total score. Therefore, they present only the results for total burnout.

Table 1 presents the means, standard deviations and Pearson inter-correlations of the variables. Each job characteristic term correlated significantly and in the expected direction with burnout. SOC showed significant positive correlations with control and support and had a negative correlation with burnout. Age and gender both correlated significantly with burnout, co-worker support and control. Age also correlated significantly with SOC and job demands.

\section{Linear effects of sense of coherence, linear and curvilinear effects of job characteristics}

As Hypothesis 1 proposes, support and control show a negative linear relationship with burnout, whereas job demands show a positive relationship with burnout (Table 2). The proposed negative relationship between SOC and work stress is significant and confirms Hypothesis 3. Hypothesis 2 explored whether job characteristics would show curvilinear relationships with burnout. Demands and supervisor
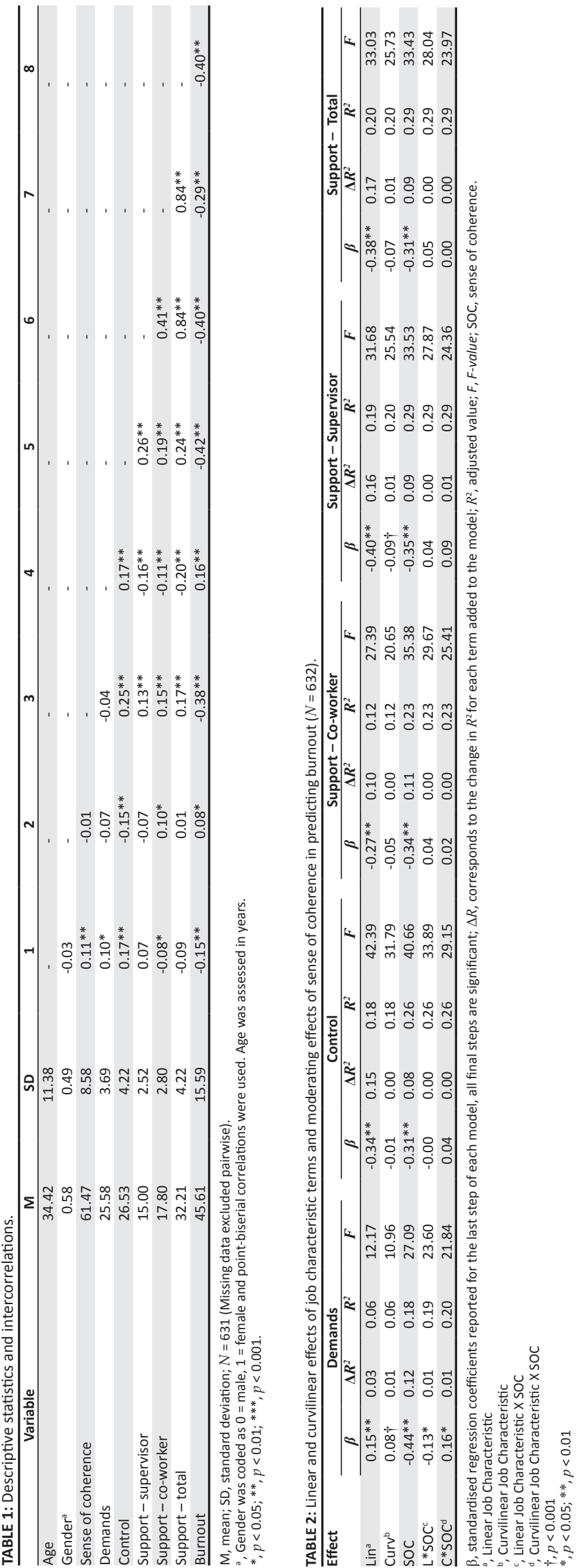
support yielded evidence of non-linear relationships with burnout and partially confirmed this hypothesis. Adding the curvilinear term to these models resulted in significant $F_{\text {change }}$ statistics for demands $F_{\text {change }}(1,577)=6.95 ; p<0.01$ and supervisor support $F_{\text {change }}(1,396)=5.14 ; p<0.05$.

Figure 1 illustrates the curvilinear effect of demands. It shows that demands that are too high or too low can result in burnout, with an increase in demands first contributing to a decrease in burnout before being associated with an increase in burnout.

Figure 2 shows the curvilinear relationship for supervisor support. It shows that a steep decrease in burnout only occurs after employees reach average levels of supervisor support. However, the shape of this relationship is different to the expected U-shape. Control, co-worker support and total support only show linear relationships with burnout with non-significant $F_{\text {change }}$ statistics for the addition of the curvilinear term to the models of control; $F_{\text {change }}(1,573)=0.170$, n.s, co-worker support; $F_{\text {change }}(1,578)=0.590$, n.s and total support; $F_{\text {change }}(1,393)=3.26$, n.s.

\section{Moderating effect of sense of coherence}

The fourth hypothesis proposed the moderating effect of SOC for both linear and curvilinear job characteristic terms. There is partial support for this hypothesis. SOC moderates the effects of linear $\left(F_{\text {change }}(1,575)=5.16 ; p<0.05\right)$ and curvilinear demands $\left(F_{\text {change }}(1,574)=9.27 ; p<0.01\right)$. For linear demands, high SOC prevents an increase in burnout even as demands increase. For those low in SOC, an increase in demands is associated with a much steeper increase in burnout.

Figure 3 shows the moderating effect of curvilinear demands. For those with low SOC, the relationship between demands and burnout is linear. However, for those with high SOC, the curvilinear effect of demands on burnout is more pronounced. This suggests that an average level of demands only results in a decrease in burnout for those with high SOC but not for those with low SOC.

For the other job characteristic models, adding the linear interaction term resulted in non-significant $F_{\text {change }}$ statistics for all the models; $F_{\text {change }}(1,571)=0.284$, n.s for control; $F_{\text {change }}(1$, $576)=1.087$, n.s for co-worker support, $F_{\text {change }}(1,394)=0.013$, $n . s$ for supervisor support and $F_{\text {change }}(1,391)=0.1 .07$, n.s for total support.

\section{Discussion}

This study considered the relationship between job characteristics and burnout in a South African sample and focused on the curvilinear effects of job characteristics. The study extended these considerations by focusing on the direct and moderating effects of SOC in predicting burnout.

\section{Job characteristics and burnout}

Concerning the first hypothesis, this study confirms the well-known notion that job characteristic variables have direct linear effects in predicting burnout (Häusser et al., 2010; Van der Doef \& Maes, 1999). Demands have a positive relationship with burnout, whilst control and social support have negative relationships with burnout.

However, we know less about the possibility of curvilinear relationships between job characteristics and burnout (De Jonge et al., 2000). Some studies find relationships contrary to the expected direction (Rydstedt, et al., 2006) whilst others find support for non-linear relationships for some outcomes but not for others (De Jonge et al., 2000). Results in this study indicated non-linear relationships between demands and burnout, and between supervisor support and burnout, thus partly confirming the second hypothesis.

The results indicated a slight $J$-shaped relationship between demands and burnout, similar to the relationship that De

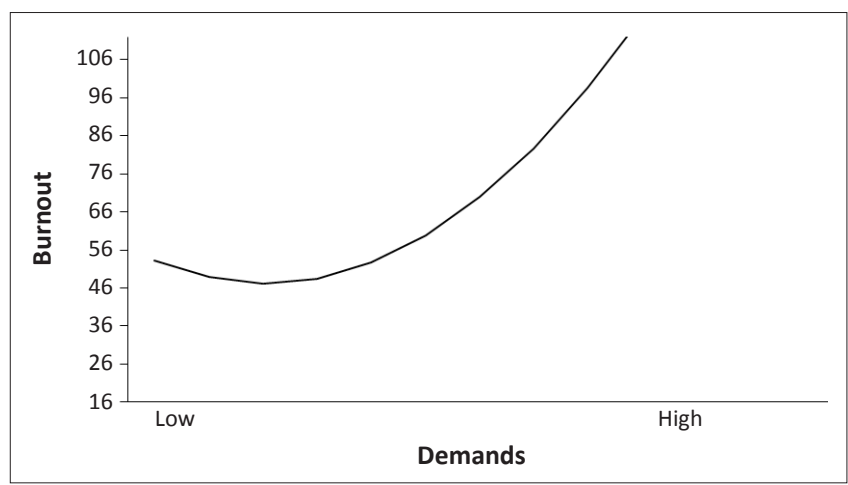

FIGURE 1: Curvilinear relationship between demands and burnout.

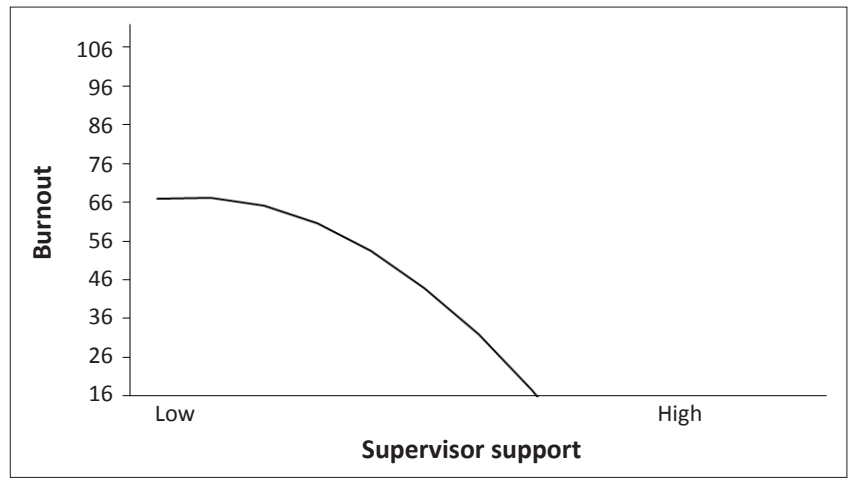

FIGURE 2: Curvilinear relationship between supervisor support and burnout.

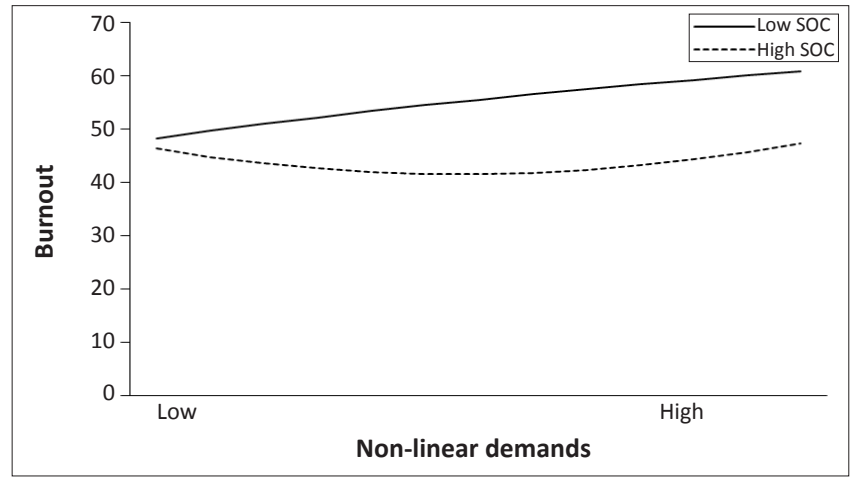

FIGURE 3: Moderating effect of sense of coherence on the relationship between non-linear demands and burnout. 
Jonge and colleagues (2000) found. The results showed that experienced burnout is lowest at an optimal level of demands whereas under- and over-stimulation can lead to distress (LeFevre et al., 2003). This confirms the authors' prediction and the previously supported propositions of the vitamin model (De Jonge \& Schaufeli, 1998; De Jonge et al., 2000; Warr, 1990). However, low demands are not as damaging as high demands - the higher the demands, the stronger the association between demands and burnout. In the case of optimal demands, people may perceive these demands as challenge stressors and not as hindrance stressors and therefore experience positive emotions, motivation and productive coping (Lepine et al., 2005), which may lower the risk of burnout. In the case of low demands, people may be bored and under stimulated (Rydstedt et al., 2006) and experience burnout (possibly indicated by reduced personal efficacy) because of lack of challenge. In the case of high demands, as demands increase, burnout continues to increase. This is possibly because of the reciprocal relationships between job characteristics and outcome variables (Häusser et al., 2010).

With regard to the non-linear relationship between supervisor support and burnout, the shape of this relationship is contradictory to the authors' second hypothesis. Previous studies have shown curvilinear relationships between support and the dimensions of burnout (De Jonge et al., 1995; De Jonge \& Schaufeli, 1998). These studies, like the current one, suggest that average levels of social support do correspond to lower levels of burnout.

However, the point of contradiction relates to how increasing levels of social support correspond to burnout. The current study suggests that burnout levels continue to decrease with increased social support (De Jonge et al., 1995; 2000). However, other work (De Jonge \& Schaufeli, 1998; 1999) suggests that increasing social support after a certain level may tend to contribute to increased burnout. This is consistent with the predictions of the vitamin model and those of this study, that increasing a job characteristic like social support may only be helpful up to a certain point, after which its effect becomes detrimental because of the stress transfer theory (Karasek et al., 1982). Contradictory results about the shape of the relationship between support and burnout may relate to the type of social support one is testing. Previous work (De Jonge et al., 1995; 2000; De Jonge \& Schaufeli, 1998; 1999) made no distinction between support that colleagues provide and that of supervisors. This makes it difficult to disentangle the true nature of the curvilinear relations based on the type of support. Differing effects of colleague and supervisor support may also be evident in different occupation groups.

In this study, control, total and co-worker support showed only linear relationships with burnout. This does not support the second hypothesis. Curvilinear relations between total support and control have been confirmed elsewhere (De Jonge \& Schaufeli, 1998; Verhoeven et al., 2003). The linear relationships for control, co-worker and total support in the current study may be because of the choice of outcome. If the authors had tested an outcome like job satisfaction (which has stronger associations with support and control), perhaps they would have found curvilinear effects (De Jonge \& Schaufeli, 1998; 1999). Clearly, factors like the choice of outcome, type of job characteristic and occupational differences cloud the exploration of non-linear relations. Therefore, we need further research in this area.

\section{Functioning of sense of coherence: A necessary consideration}

With regard to the functioning of SOC in relation to burnout, the study confirms previous research findings that indicate the direct effect of SOC: people with a higher SOC experience less burnout (Rothmann et al., 2003; Söderfeldt et al., 2000; Van der Colff \& Rothmann, 2009). As a general orientation, SOC does appear to help with successful coping and helps to reduce burnout. This supports the third hypothesis.

Finally, with regard to hypothesis four, the study confirms evidence for SOC as a moderator variable. This effect clarifies the conditions under which demands will affect burnout and the strength of this effect. Given the curvilinear relationship between demands and burnout, the authors have given attention to SOC's moderating effect on this relationship. Previous research has not considered the possibility that individual characteristics may moderate the curvilinear effects (Häusser et al., 2010). Therefore, this study shows how the demand-burnout relationship differs for those with high and low SOC.

For those low in SOC, the relationship between demands and burnout is linear. An increase in demands corresponds to an increase in burnout. This suggests that the effects of job demands are more detrimental for those with low SOC. However, for those with high SOC, the relationship is slightly curvilinear. This suggests that an optimal level of demands corresponds to lower burnout. Individual differences underpin the concept of an optimal level of demands: 'the distressful or eustressful nature of any particular stimulus is governed by how one interprets it and chooses to react to it' (LeFevre et al., 2003, p. 730). People high in SOC are more likely to benefit from an optimal level of demands because they can capitalise on available resources and manage the demands better. For those high in SOC, an initial increase in demands may actually reduce burnout slightly. People with high SOC need quite high demands to result in an increase in burnout. Researchers have found similar differential job characteristic-strain relationships in people with high and low emotional stability (Rubino et al., 2012).

This study adds to this growing body of literature that emphasises the necessity to consider individual and job characteristics jointly. The authors found no evidence of the moderating effect of SOC on control and support. This fails to support hypothesis four. A possible explanation is that SOC may only have a protective function, by acting as a buffering resource, in the case of low support and control (Hanse \& Engström, 1999). Mean scores for control and support are 
quite high in this study. This suggests that there are limited opportunities for SOC to act as a moderator and compensate for the lack of job resources.

\section{Limitations and directions for future research}

The study is cross-sectional. This means that it is impossible to infer causation. The relationship between burnout and job characteristics may be bi-directional and the relationship between SOC and job characteristics may be reciprocal (De Beer et al., 2013; Häusser et al., 2010). Consequently, longitudinal research, which explores relationships that are more detailed between the dimensions of SOC, job characteristics and burnout whilst considering linear and curvilinear effects, is necessary. Research that includes subjective and objective measures of job characteristics would be ideal (Häusser et al., 2010) because using selfreporting measures leads to common method variance that may bias the regression coefficients (Antonakis et al., 2010).

However, this may not be a problem for tests of moderation because bias should not result in an overestimation of the interactive effects (Van der Doef \& Maes, 1999). The authors entered quadratic terms before the interaction terms in the regression models. This may result in a loss of power or unstable regression coefficients (Ganzach, 1997). Conversely, if one does not control for curvilinear relationships, the interaction effects one observes could be incorrect (Fletcher \& Jones, 1993).

The sample was not representative. Therefore, replication studies in samples that are more representative are necessary and in occupation or sector specific samples because the nature of job characteristics may vary in different groups.

\section{Practical implications}

The focus of an intervention may differ depending on whether a certain individual characteristic provides an explanation of when or why one factor affects another. The moderating effect of SOC on demands is a promising finding.

Organisations can help to develop SOC by providing information in a structured and consistent manner, by equipping employees with the necessary resources to perform their jobs, allowing them to exercise independence and become involved in making decisions (Van der Colff \& Rothmann, 2009). Organisations can also intervene at the level of the stressor and address high levels of job demands through activities like redesigning jobs, flexible work schedules and setting goals (Rothmann, 2003). Furthermore, organisations need to design interventions with sector or industry specific requirements in mind.

The shape of the relationship between job characteristics and strain outcomes has implications for the practical management of stress (LeFevre et al., 2003). Linear relationships suggest that organisations can use a population approach to stress management to increase resources and decrease stressors for everyone. The assumption is that this will improve well being for everyone and that everyone will respond to the intervention in the same way (Rydstedt et al., 2006). However, curvilinear relationships imply optimising the level of the stressor until a certain point. However, here an organisation cannot use a population approach (Rydstedt et al., 2006). When an organisation uses a population approach to prevention, the presence of a non-linear relationship between a stressor and strain outcome (as is the case with demands) will result in increased risk for some people (Adams \& White, 2005).

Finally, managing the job characteristic-strain relationship requires an understanding of the individual response. Therefore, managers need to help people to interpret stressors as challenge stressors and focus on understanding the individual response to workplace characteristics (LeFevre et al., 2003; Rubino et al., 2012). Stress management programmes, or those that promote an awareness of available resources and boost people's capacity to use these resources, may help people to manage their responses to job stressors and demands.

\section{Conclusion}

This study suggests that it is worth considering the curvilinear effects of job characteristics and that more specific measures of job characteristics may be necessary to obtain a clearer understanding of these effects for practical and theoretical reasons.

Jointly considering individual and job characteristics in predicting burnout is useful. The negative effects of job control and social support on burnout seem independent of the negative effect that SOC has on burnout: SOC does not moderate social support and control. However, one cannot understand the effect of demands on burnout fully unless one considers SOC jointly with demands. The different effects of demands on burnout for people high and low in SOC suggests that it is not merely the presence or absence of a job characteristic that it is important for well-being outcomes, but how people respond to its presence or absence.

\section{Acknowledgements}

A grant to Jérôme Rossier, Koorosh Massoudi, and Gideon De Bruin (Swiss South African Joint Research Programme grant no 11) from the State Secretariat for Education and Research (SER) partially financed this research. This publication results from research works conducted within the framework of the National Competence Center in Research LIVES, which the Swiss National Science Foundation finances. The authors are grateful to the Swiss National Science Foundation for its financial support.

\section{Competing interests}

The authors declare that they have no financial or personal relationship(s) that may have inappropriately influenced them when they wrote this article. 


\section{Authors' contributions}

C.S.J. (University of Johannesburg and University of Lausanne) completed this research in partial fulfilment of the requirements for her Mphil in industrial psychology under the supervision of G.P.D (University of Johannesburg) and M.G. (University of Johannesburg). G.D.P (University of Johannesburg) proposed the study design, assisted with the analysis, theoretical sections and provided overall expert advice. C.G (University of Lausanne) assisted with data collection and made theoretical contributions. M.G. (University of Johannesburg) assisted with the theoretical overview and discussion. K.M (University of Lausanne) provided comments on the overall manuscript and J.R. (University of Lausanne) provided expert advice and gave statistical and theoretical contributions.

\section{References}

Adams, J., \& White, M. (2005). When the population approach to prevention puts the health of individuals at risk. International Journal of Epidemiology, 34, 40-43. $\mathrm{http}: / / \mathrm{dx}$.doi.org/10.1093/ije/dyh232

Antonakis, J., Bendahan, S., Jacquart, P., \& Lalive, R. (2010). On making casual claims: A review and recommendations. The Leadership Quarterly, 21, 1086-1120. http:// dx.doi.org/10.1016/j.leaqua.2010.10.010

Antonovsky, A. (1979). Health, stress and coping. San Francisco, CA: Jossey-Bass.

Antonovsky, A. (1987). Unravelling the mystery of health: How people manage stress and stay well. San Francisco, CA: Jossey-Bass.

Antonovsky, A. (1993). The structure and properties of the sense of coherence scale. Social Science \& Medicine, 36, 725-733. http://dx.doi.org/10.1016/02779536(93)90033-Z

Beehr, T.A., Bowling, N.A., \& Bennett, M.M. (2010). Occupational stress and failures of social support: When helping hurts. Journal of Occupational Health Psychology 15, 45-59. http://dx.doi.org/10.1037/a0018234

Brewer, E.W., \& Shapard, L. (2004). Employee burnout: A meta-analysis of the relationship between age or years of experience. Human Resource Development Review, 3, 102-123. http://dx.doi.org/10.1177/1534484304263335

Cohen, J., Cohen, P., West, S.G., \& Aiken, L.S. (2002). Applied Multiple Regression/ Correlation Analysis for the Behavioral Sciences (3rd ed.). New York, NY: Routledge Academic.

De Beer, L.T., Pienaar, J., \& Rothmann, Jr.S., (2013). Investigating the reversed causality of engagement and burnout in the job demands-resources theory. SA Journal of Industrial Psychology, 39(1), Art. \#1055, 9 pages.

De Jonge, J. (1995). Job autonomy, well being, and health: A study among Dutch health care workers (Doctoral dissertation). Masstricht, The Netherlands: Datawyse.

De Jonge, J., Reuvers, M.M.E., Houtman, I.L.D., Bongers, P.M., \& Kompier, M.A.J. (2000). Linear and nonlinear relations between psychosocial job characteristics, subjective outcomes, and sickness absence: Baseline results from SMASH. Journal subjective outcomes, and sickness absence: Baseline results from SMASH. Journal
of Occupational Health Psychology, 5, 256-268. http://dx.doi.org/10.1037/1076of Occupation
8998.5.2.256

De Jonge, J., \& Schaufeli, W.B. (1998). Job characteristics and employee well-being a test of Warr's Vitamin Model in health care workers using structural equation a test of Warr's Vitamin Model in health care workers using structural equation modelling. Journal of Organizational Behavior, 19, 387-407. http://dx.doi.
org/10.1002/(SICI)1099-1379(199807)19:4\%3C387::AID-JOB851\%3E3.0.CO;2-9

De Jonge. J., \& Schaufeli, W.B. (1999). An empirical test of the Vitamin Model in health care workers: Effects of job satisfaction and burnout. In P. M. Le Blanc, M.C.W. Peeters, A. Büssing \& W.B. Schaufeli (Eds.), Organizational Psychology and Health Peeters, A. Büssing \& W.B. Schaufeli (Eds.), Organizational Psychology and Health
Care: European Contributions (pp. 85-99). Meiring, Netherlands: Rainer Hampp Verlag.

Feldt, T. (1997). The role of sense of coherence in well-being at work: Analysis of main and moderator effects. Work \& Stress: An International Journal of Work, Health \& Organisations, 11, 134-147. http://dx.doi.org/10.1080/02678379708256830

Feldt, T., Kivimäki, M., Rantala, A., \& Tolvanen, A. (2004). Sense of coherence and work characteristics: A cross-lagged structural equation model among managers. Journal of Occupational and Organizational Psychology, 77, 323-342. http:// dx.doi.org/10.1348/0963179041752655

Feldt, T., Metsäpelto, R.., Kinnuen, U., \& Pulkkinen, L. (2007). Sense of coherence and five-factor approach to personality: Conceptual relationships. European Psychologist, 12, 165-172. http://dx.doi.org/10.1027/1016-9040.12.3.165

Fletcher, B.C., \& Jones, F. (1993). A refutation of Karasek's demand-discretion model of occupational stress with a range of dependent measures. Journal of Organizational Behavior, 14, 319-330. http://dx.doi.org/10.1002/job.4030140404

Ganzach, Y. (1997). Misleading interaction and curvilinear terms. Psychological Methods, 2, 235-247. http://dx.doi.org/10.1037/1082-989X.2.3.235

Györkös, C., Becker, J., Massoudi, K., De Bruin, G.P., \& Rossier, J. (2012). The impact of personality and culture on the job-demands-control model of job stress. Swiss Journal of Psychology, 71, 21-28. http://dx.doi.org/10.1024/1421-0185/a000065
Hanse, J.J., \& Engström, T. (1999). Sense of coherence and ill health among the unemployed and re-employed after closure of an assembly plant. Work \& Stress, 13, 204-222. http://dx.doi.org/10.1080/026783799296020

Häusser, J.A., Majzisch, A., Niesel, M., \& Schulz-Hardt, S. (2010). Ten years on: A review of recent research on the Job Demand-Control (-Support) model and general psychological wellbeing. Work \& Stress, 24, 35-70. http://dx.doi. org/10.1080/02678371003683747

Hochwälder, J. (2006). An empirical exploration of the effect of personality on general and job-related mental ill-health. Social Behavior and Personality, 34, 1051-1070. http://dx.doi.org/10.2224/sbp.2006.34.9.1051

Johnson, J.V., \& Hall, E.M. (1988). Job strain, work place social support, and cardiovascular disease: A cross-sectional study of a random sample of the cardiovascular disease: A cross-sectional study of a random sample of the
Swedish working population. American Journal of Public Health, 78, 1336-1342. http://dx.doi.org/10.2105/AJPH.78.10.1336

Karasek, R.A. (1979). Job demands, job decision latitude, and mental strain: Implications for job redesign. Administrative Science Quarterly, 24, 285-308. http://dx.doi.org/10.2307/2392498

Karasek, R.A., Triantis, K.P., \& Chaudry, S.S. (1982). Coworker and supervisor support as moderators of associations between task characteristics and mental strain Journal of Occupational Behavior, 3, 181-200. http://dx.doi.org/10.1002/ job.4030030205

LeFevre, M., Matheny, J., \& Kolt, G.S. (2003). Eustress, distress, and interpretation in occupational stress. Journal of Managerial Psychology, 18, 726-744. http:// dx.doi.org/10.1108/02683940310502412

Lepine, J.A., Podsakoff, N.P., \& Lepine, M.A. (2005). A meta-analytic test of the challenge stressor-hindrance stressor framework: An explanation for the inconsistent relationships among stressors and performance. The Academy of Management relationships among stressors and performance. The Academy of $M$,
Journal, 48, 764-775. http://dx.doi.org/10.5465/AMJ.2005.18803921

McCrae, R.R., \& Costa, P.T. (1994). The stability of personality: Observations and evaluations. Current Directions in Psychological Science, 3, 173-175. Retrieved from http://www.jstor.org/stable/20182303 http://dx.doi.org/10.1111/14678721.ep10770693

Maslach, C. \& Jackson, S.E. (1986). Maslach Burnout Inventory. Manual (2nd ed.). Palo Alto, CA: Consulting Psychologists Press.

Maslach, C. \& Goldberg, J. (1998). Prevention of burnout: New perspectives. Applied \& Preventative Psychology, 7, 63-74. http://dx.doi.org/10.1016/S09621849(98)80022-X

Maslach. C., Schaufeli, W.B., \& Leiter, M.P. (2001). Job burnout. Annual Review of Psychology, 52, 397-422. http://dx.doi.org/10.1146/annurev.psych.52.1.397

Pedrabissi, L, Rolland, J.P., \& Santinello, M. (1993). Stress and burnout among teachers in Italy and France. The Journal of Psychology: Interdisciplinary and Applied, 127 529-535. http://dx.doi.org/10.1080/00223980.1993.9914889

Piedmont, R.L. (1993). A longitudinal analysis of burnout in the health care setting: The role of personal dispositions. Journal of Personality Assessment, 61, 457-473.

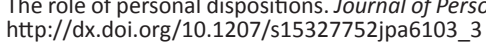

Rothmann, S. (2003). Burnout and engagement: A South African perspective. South African Journal of Industrial and Organisational Psychology, 29(4), 16-25. http:// dx.doi.org/10.4102/sajip.v29i4.122

Rothmann, S., Jackson, L.T., \& Kruger, M.M. (2003). Burnout and job stress in a local government: The moderating effect of sense of coherence. SA Journal of Industria Psychology, 29(4), 52-60. http://dx.doi.org/10.4102/sajip.v29i4.122

Rubino, C., Perry, S.J., Milam, A.C., Spitzmueller, C., \& Zapf, D. (2012). DemandControl-Person: Integrating the Demand-Control and Conservation of Resources
Models to test and expanded stressor-strain model. Journal of Occupational Models to test and expanded stressor-strain model. Journal of Occup
Health Psychology, 17, 456-472. http://dx.doi.org/10.1037/a0029718

Rydstedt, L.W., Ferrie, J., \& Head, J. (2006). Is there support for curvilinear relationships between psychosocial work characteristics and mental well-being? Cross-sectional and long-term data from the Whitehall II study. Work \& Stress, 20, 6-20. http://dx.doi.org/10.1080/02678370600668119

Schaufeli, W.B. (2003). Past performance and future perspectives of burnout research. SA Journal of Industrial Psychology, 29, 1-15. http://dx.doi.org/10.4102/sajip. v29i4.127

Schaufeli, W.B., \& Salanova, M. (2007). Efficacy or inefficacy, that's the question: Burnout and work engagement, and their relationships with efficacy beliefs. Anxiety, Stress, and Coping, 20, 177-196. http://dx.doi.org/10.1080/10615800701217878

Schmidt, K-H., \& Diestel, S. (2011). Differential effects of decision latitude and control on the job demands-strain relationship: A cross sectional survey study among
elderly care nursing staff. International Journal of Nursing Studies, 48, 307-317. elderly care nursing staff. International Journal of
$\mathrm{http} / / / \mathrm{dx}$.doi.org/10.1016/j.ijnurstu.2010.04.003

Söderfeldt, M., Söderfeldt, B., Ohlson, C.G., Theorell, T., \& Jones, I. (2000). The impact of sense of coherence and high-demand/low-control job environment on selfreported health, burnout, and psychophysiological stress indicators. Work \& Stress, 14, 1-15. http://dx.doi.org/10.1080/026783700417195

Tremblay, M.A., \& Messervey, D. (2011). The Job Demands-Resources model: Further evidence for the buffering effect of personal resources. SA Journal of Industria Psychology, 37(2), Art. \#876, 10 pages. http://dx.doi.org/10.4102/sajip.v37i2.876

Van der Colff, J.J., \& Rothmann, S. (2009). Occupational stress, sense of coherence, coping, burnout and work engagement of registered nurses in South Africa. SA Journal of Industrial Psychology, 35(1), Art. \#423, 10 pages. http://dx.doi. org/10.4102/sajip.v35i1.423

Van der Doef, M., \& Maes, S. (1999). The Job Demand-Control (-Support) Model and psychological well-being: a review of 20 years of empirical research. Work \& Stress, 13, 87-114. http://dx.doi.org/10.1080/026783799296084

Verhoeven, C., Maes, S., Kraaij, V., \& Joekes, K. (2003). The job demand-control-social support model and wellness/health outcomes: A European study. Psychology and Health, 18, 421-440.

Warr, P.B. (1990). Decision latitude, job demands, and employee well-being. Work \& Stress, 4, 285-294. http://dx.doi.org/10.1080/02678379008256991 